\title{
Management of Urban Wastewater in the City of Maradi (Niger): The Case of Domestic Wastewater
}

\author{
Saidou Hassidou*, Laminou Ary Mahaman Moustapha \\ Faculty of Sciences and Techniques, University Dan Dicko Dankoulodo of Maradi, Niger Republic \\ Email: saidouhassidou@gmail.com, "saidouhassidou@yahoo.fr
}

Received 4 April 2015; accepted 30 April 2015; published 8 May 2015

Copyright (C) 2015 by authors and Scientific Research Publishing Inc. This work is licensed under the Creative Commons Attribution International License (CC BY). http://creativecommons.org/licenses/by/4.0/

(c) $\underset{\mathrm{EY}}{\mathrm{BY}}$ Open Access

\section{Abstract}

Uncontrolled urbanization of African cities and the lack of municipal waste management services in these cities make landscapes become places of multiple and varied interactions between health and environment. In this sense, under strong urban growth in a context of sub-equipment sanitation, the city of Maradi doesn't escape to this situation which results in the spread of pollution (release of unpleasant odors, and proliferation of mosquitoes) and many diseases posing multiple health problems. Our study focuses only on liquid waste especially domestic wastewater. To study the different domestic wastewater management options in the town of Maradi, a survey was conducted among 340 households in 17 districts. We note in most cases a crucial of waste management infrastructure (drainage and wastewater treatment) in the city. Thus, only the individual sanitation facilities are used. In the town of Maradi, in addition to the storm drains, there are, in old districts, ditches that discharge wastewater and unfortunately end up in rivers without treatment. Total domestic wastewater production is estimated at $86761.28 \mathrm{~m}^{3}$ per day. This water is mostly from laundry activities, bathing, dishes, and is discharged in large part through the streets, by more than $60 \%$ of households. Also, pit emptying is performed at $39.11 \%$ by the vehicle Peugeot tank. The quality of service rendered by an actor is very important to encourage households to join. Existing autonomous sanitation facilities are poorly designed and poorly maintained. Fecal sludge is dumped in a hole near saturated latrines; this work is mainly done by manual scavengers or dumped in fields or on nearby vacant land concessions.

\section{Keywords}

Management, Urban Wastewater, Domestic Wastewater, Maradi, Niger

\footnotetext{
${ }^{*}$ Corresponding author.
} 


\section{Introduction}

In Niger, West African country, rainfall is the determining factor in climate. Indeed, rainfall ranging from South to North is irregular and poorly distributed in time and space. The far South receives more than $800 \mathrm{~mm}$ of rainfall per year; the rainfall decreases rapidly in a Southwest-Northeast axis, and lowers to less than $100 \mathrm{~mm}$ in the north and east of the country. Thus, since the great droughts of the year 1970 and the year 1980, Niger has been facing an accelerated environmental degradation under the combined action of natural and anthropogenic factors making natural resources vulnerable; especially, the surface and ground waters are threatened by the cumulative effects of recurrent droughts, desertification and human activities. Therefore, the changes are much observed in the Maradi region located in the south central part of Niger. This region has an area of about $41,796 \mathrm{~km}^{2}(3 \%$ of the country) and a population of 3,117,810 inhabitants, representing $20.20 \%$ of Niger. It also records the highest poverty rates in the country (73.4\%) in 2008, which greatly contributes to the urbanization of the city of Maradi. Furthermore, in large African cities, several factors make difficult the urban sanitation control and the access to clean water. In this sense, the strong demographic growth is accompanied by an anarchic space development that is out of control of public authorities. Populations settled without the ability to access to urban services. The same disturbing phenomenon is observed in the town of Maradi that exposes people to multiple environmental and public health problems mainly related to poor sanitation. Around the world, including in developed countries, there is a serious problem of wastewater to the point that policymakers have adopted emergency policies to better manage water resources [1]. The problem of wastewater in West and Central Africa is a subject that remains unsolved, despite numerous initiatives to date. Most African cities are built without a thorough reorganization plan, which now makes search solution complex. Collection systems and treatment of wastewater and excreta are underdeveloped or nonexistent. The aim of this study was to investigate how domestic wastewater was managed in the city of Maradi, economic capital of Niger, and propose solutions to improve this management. It was necessary to list the different types of domestic wastewater and management modes, to establish a link between wastewater management and poverty, to obtain information on the perception of households to different modes discharge of waste water, to understand the state of neighborhoods in terms of drainage facilities wastewater (gutters and collectors) and compare managements among neighborhoods, and to have an idea of the autonomous wastewater management in the town of Maradi.

\section{Materials and Methods}

\subsection{Presentation of the Study Area}

Our study area is the town of Maradi limited: in the North by the urban commune of Tibiri Gobir, to the East and South by the rural commune of Djirataoua, to the West by the rural communes of Sarkin Yamma and Sofo.

According to the National Institute of Statistic, the population of this city is estimated, in 2012, at 264,897 inhabitants distributed as following: 134,133 male and 130,764 female sexes with a growth rate of 3.4. The town of Maradi covers an area of $20 \mathrm{~km}^{2}$.

The list of districts in Maradi City with their heads is given in Table 1.

\subsection{Field Equipment}

As a tool, we used an interview guide for the collection of data from individual interviews with the persons responsible for the management of municipal wastewater services, a digital camera, the observation sheets to mention the observations made in the field, and a semi-structured questionnaire to collect some data at the household of the various districts of the city of Maradi.

\subsection{Laboratory Equipment}

For data processing we used a laptop allows us to store and output the data, excel for calculations and realization of graphics, SPSS software to calculate the standard deviation, the averages, standard error of average etc.

\subsection{Methodology}

The study focuses specifically on the management of urban wastewater of the city of Maradi, the case of domestic wastewater. To achieve the objectives of this study we have adopted a methodological approach that includes 
Table 1. List of districts in the city of Maradi with their heads.

\begin{tabular}{cccc}
\hline Number order & Name of district head & Phone & Districts \\
\hline 1 & Kabirou Maradi Maazou & +22796286873 & Maradaoua \\
2 & Harouna Galadima & +22796666858 & Yandaka \\
3 & Illili Dan Badaou & +22796118380 & Souzou Dan Zambadi \\
4 & Laouali Idi & +22796103830 & Hassaou \\
5 & Rabé Hassaou & +22796136259 & Soura Alladèye \\
6 & Idi Almou & +22796832897 & Nouveau Carré \\
7 & Amadou Issa & +22796972035 & Zaria 2 \\
8 & Salissou MijinYawa & +22796436878 & Zaria 1 \\
9 & Laouali Gonda & +22796686483 & Limantchi \\
10 & Abdoulaye Miko & +22796722018 & Mazadou Jika \\
11 & Liman Almou Moussa & +22796894723 & Bagalam \\
12 & Laouali Dan Abdou & +22798363362 & Mokoyo \\
13 & Moussa Soly & +22796505646 & Ali Dan Sofo \\
14 & Sani Dan Baba & +22797055195 & Dan Goulbi \\
15 & Bouzou Dan Galadima & +22796881195 & Adamou Bagalam \\
\hline 16 & Illa Charifi & +22796959352 & Sari \\
\hline
\end{tabular}

the following steps: Literature search, sampling, data collection, and data analysis

\subsubsection{Literature Search}

The consultation has involved not only documents but also general briefs end of study, project reports and information technology services related to the topic of study. This helped to review the information and existing data.

\subsubsection{Sampling}

The survey was conducted in 17 districts of the city of Maradi with particular emphasis on the old districts namely, Maradaoua, Bagalam, Yandaka, Limantchi and Assaou (Table 1). Putting emphasis on these areas is based on the fact that they received the intervention of Hygiene and Sanitation Project whose ultimate goal is the consistent management of sanitation in general and the liquid component in particular.

The survey method is simple random sampling. It first was to select in each neighborhood a household is considered the starting point of sampling; the following was selected as a sampling interval of 5 houses.

This method has identified a total sample of 340 households, 20 households by district.

Questions were addressed to the heads of the sampled households (male or female) considered as the respondents of survey or another person designated by them.

\subsubsection{Data Collection}

Questionnaire:

To collect information and data related topic, it was then made to the administration at the household of a questionnaire with the related topics:

Drinking water supply system;

Production and disposal of gray wastewater; 
Domestic precautions taken by households to ensure environmental and health-related quality garbage pits; Management of household waste;

Nuisance from neighborhoods during the rainy season;

Looking for solutions against the problems of the district.

\subsubsection{Field Observations}

The realization of this research has led us to perform many field trips. This shift has allowed us to make a general overview on the hygiene and sanitation status in the various districts and verify the information collected from the population.

Also during these trips, we took every opportunity to visit:

- Sites where wastewater is discharged after emptying pits;

- The place where the waste water discharged by some municipal gutters throw themselves;

- As the state of the streets in the town of Maradi.

Information collected from households was then supplemented or face with other data from various sources (surveys in homes, individual interviews and desk research).

\subsubsection{Data Analysis}

The collected data is subject to a semi codification. Then we perform grouping of information by households and variables in the tables. The relative frequencies of each variable were calculated relative to the number of households surveyed. Finally, curves and graphs are plotted to better illustrate the results obtained. These treatments were conducted with Word and Excel.

\subsubsection{Difficulties}

As part research theme perfectly with the activities should realize the Department of Hygiene and Sanitation, we had to convince the heads of households to agree to answer our questions. This was not an easy task because many are afraid to be amended. In the same respect for the proposed sampling had raised many questions from people who have realized.

Another difficulty lies in the fact that during conversations, people claimed to have been questioned in the past and in the same framework of certain projects and they got nothing for their participation.

\section{Results and Discussion}

\subsection{Presentation and Analysis of Observational Data}

\section{Inventory Management of Wastewater from Septic Tanks and Drain Sludge}

Picture 1 presents a pumper truck spirited pour its contents fraudulently approximately $100 \mathrm{~m}$ of "KADRO" on the place of deposit garbage. Also another strategy, but opted constantly worrying in the town of Maradi is to dig a septic side hole to pour its contents (Picture 2).

The results of field observations illustrated in Picture 1 and Picture 2 showed that the wastewater and sewage sludge are dumped haphazardly and uncontrolled in the town of Maradi without any treatment. This could be explained by the absence of domestic wastewater treatment plants and faecal sludge, but also by the lack of monitoring and environmental control system for sanitation, which has a significant impact production of wastewater in the city. This is in agreement with the study of Hèssouwè (2011) in the city of Lomé (Togo) [2]. As against the study of Essinga (2014) in the town of Bertoua in Cameroon which is not in agreement of our results [3]. It showed that these types of water are treated by a wastewater treatment plant before being discharged into the environment. This explains the lack of enlistment of our sanitation leaders.

\subsection{Current Situation of Laundry Wastewater Management in the Town of Maradi}

In the town of Maradi, wastewater management differs from one household to another even within a district. Picture 3 and Picture 4 showed two different modes discharge gray wastewater in households. Picture 3 shows a specially constructed device to drain the waters of laundry and washing utensils at an inhabitant of Maradaoua district. This explains the awareness of some households of negative impacts that may result from the uncontrolled discharge of waste water. 


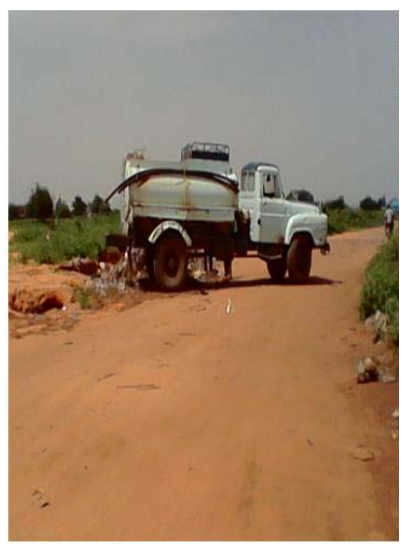

Picture 1. A pumper truck pouring its contents fraudulently (Kadro: district of Zaria 2).

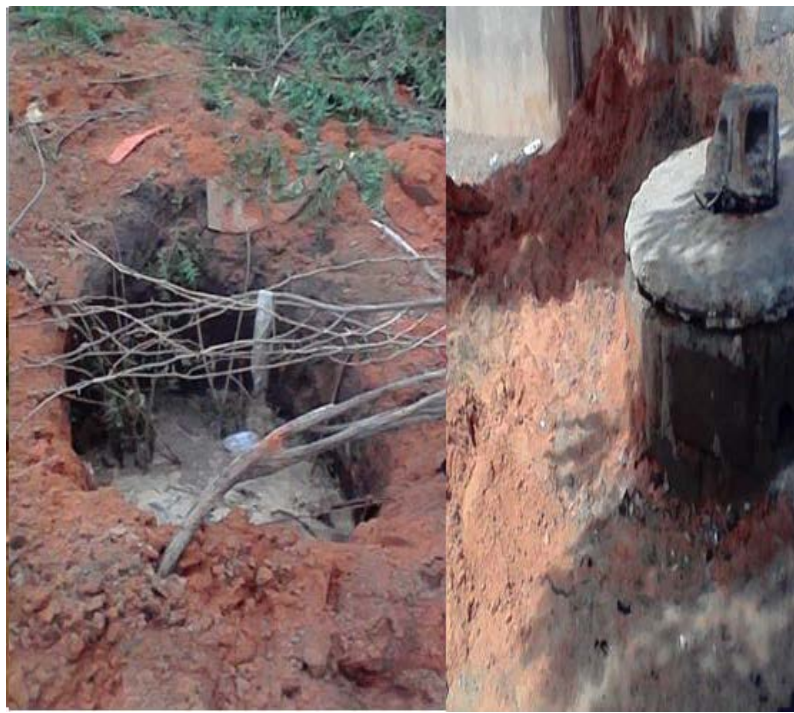

(a)

(b)

Picture 2. (a) and (b) wastewater from a septic tank emptied into a hole near, at the district Bourja.

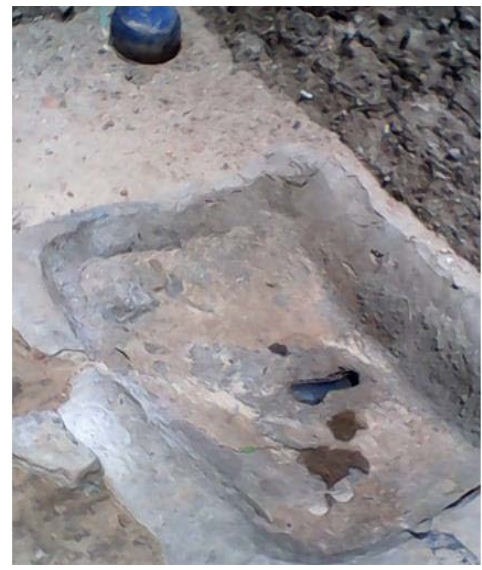

Picture 3. A device of management of gray wastewater from 1987 connected to a gutter at Maradaoua district. 


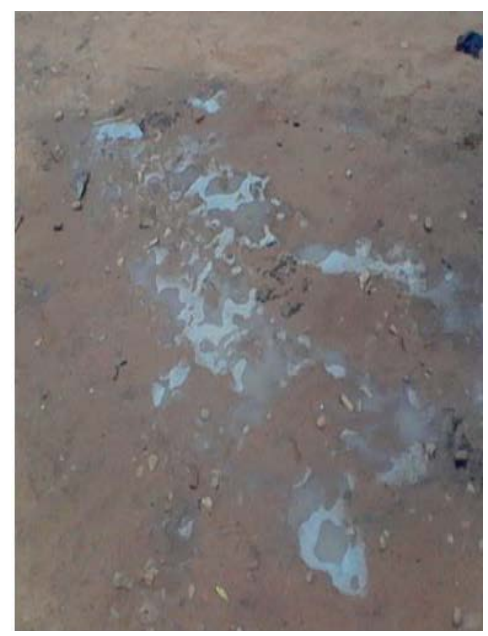

Picture 4. Laundry wastewater discharged into a street at Bourja district.

\subsection{Inventory Management of Autonomous Sanitation Effluents in Some Districts of the City of Maradi}

In the town of Maradi, particularly at older neighborhoods (Maradaoua, Bagalam, Yandaka, Mokoyo, etc.), the collection and disposal of stormwater drains are made through a network and open manifolds. They are made difficult by the anarchic occupation of space and the use of the network for other purposes such as discharge of domestic sewage, garbage dumps and faecal sludge and sometimes as places of defecation. Thus, Picture 5 shows autonomous sanitation effluents that drain gutters by collectors while pouring directly without any treatment in "Dan Tabkin Alatou" in Assaou neighborhood. According to information obtained it is a repository of garbage arranged for nearby settlements (see appendix sheet No. 1). Also the field observations led us to find the gutters at Bagalam neighborhood that do not played the role of sewage, but rather points of water stagnation favoring the proliferation of disease vectors, and sometimes cause floods with disastrous consequences on people and their property (Picture 6). Thus, some interviewees confirm the lack of dumps in Assaou Limantchi, Bagalam and Yandaka neighborhoods. Which can justify the presence of household waste in gutters (plastics, bottles, cardboard, etc.) and requires some districts to transform the edges of the water points in wild dumps "case of Tabkin Dan Alatou", the district of Assaou (Picture 7). The study of Essinga (2014) in the town of Bertoua in Cameroon confirms our results [3].

In other areas septic tanks are represent the evils. However, some neighboring pits are full and do not bailed until the overflow is discharged to the neighbors' downstream, causing conflicts between households (Picture 8). This result could be explained by the fact that the evacuation equipments wastewater are very old and are often poorly constructed and poorly maintained but especially to recklessness, bad faith owners.

As in other areas, gutters and collectors networks are completely filled with sand (Picture 9). This could be explained by inadequate or even non-existent drainage systems of rainwater (gutters and collectors) in the city, especially in the suburbs. So that rain water flows directly from the streets to the gutters. In the case of paved streets, this evacuation is done well enough. Unfortunately, most of the streets in the town of Maradi are sandy, which favors the silting of drains.

\subsection{Presentation and Analysis of Interview Data}

When we try to see the percentages of different types of wastewater produced (Table 2), we see that there is a net change. And in household surveys the suds, toilets and dishes are produced in $100 \%$. This result could be explained by the fact that the generating activities of these types of water are part of the daily needs of man. As against the $14.70 \%$ of the room wiping water is due to a large number of clay constructions, especially in older neighborhoods but also the degree of cleanness in households. Thus the low wash water motorbike/car (13.5) could be explained on the one hand, by poverty (households lack of moving means), on the other hand to the influence of stations washing vehicles that perform tasks outside of households. 


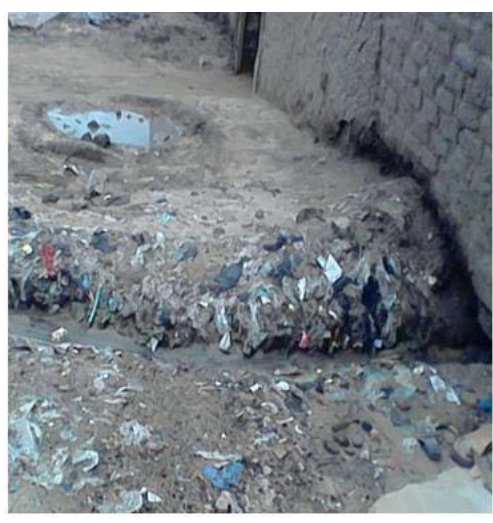

(a)

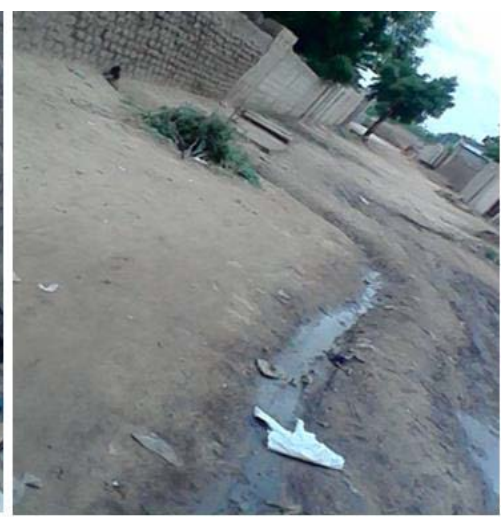

(b)

Picture 5. Disposal systems gray waste water of households connected to public roads in the town of Maradi ((a) Yandaka district; (b) Bourja district).

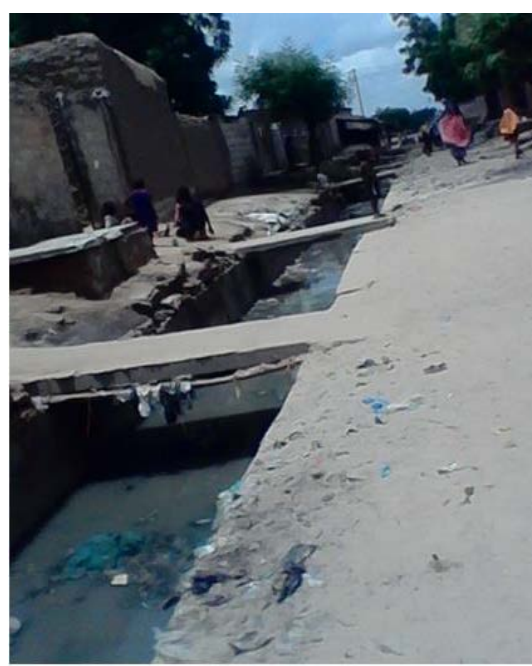

Picture 6. Open gutter and stagnating wastewater following the deposit of garbage (Bagalam district).

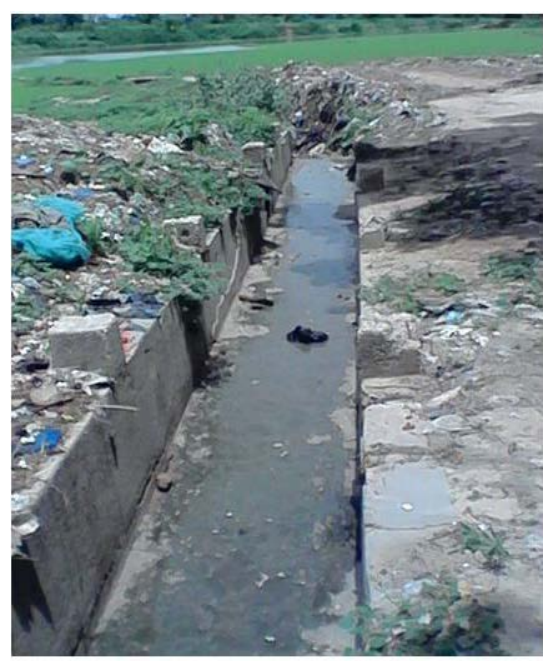

Picture 7. A drainage gutter wastewater jumping directly into Tabkin Dan Alatou (Assaou district). 


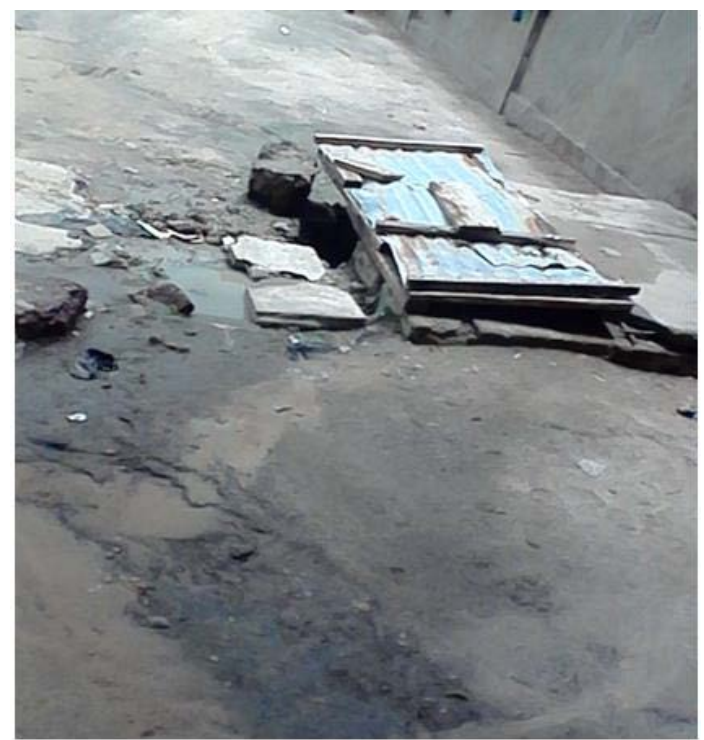

Picture 8. Septic shabby spilling its overflow downstream (Dan Goulbi district).

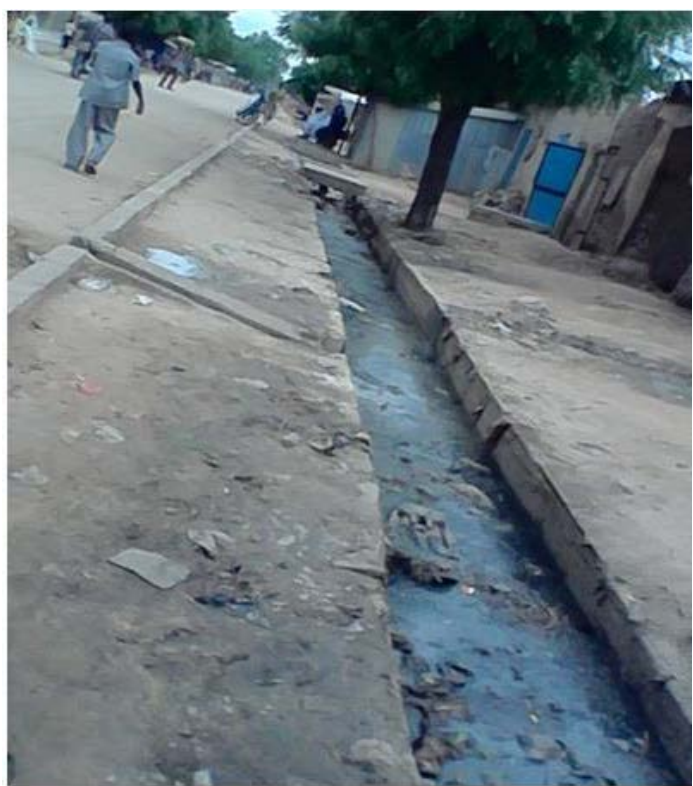

Picture 9. Poorly maintained gutter and filled with sand (sabon gari district).

Table 2. Global distribution of the surveys for different types of wastewater produced.

\begin{tabular}{ccc}
\hline Type of wastewater & Frequency & Percentage \\
\hline Laundry & 340 & 100 \\
Toilet & 340 & 100 \\
Washing up & 340 & 100 \\
Wiping rooms & 50 & 14.70 \\
Washing car/motorbike & 46 & 13.5 \\
\hline
\end{tabular}


Table 3 highlights that $72.95 \%$ of surveyed households do not own the SEEUG against $27.05 \%$ that wicks their gray wastewater within households outward (on public roads). This result is explained by a lack of monitoring and awareness by the technical services for sanitation in different districts.

In this part, the knowledge of the amount of waste water produced on average by the interviewee and the number of people supported by each head of household helped us to estimate the amount of wastewater produced by each municipality by extrapolation. Table 4 shows soft different amounts of wastewater produced in the three municipalities. Overall the average amount of wastewater produced by a person in the town of Maradi is $32.02 \mathrm{~L}( \pm 1.19)$. Thus the estimate of the amount of waste water is a basic element for infrastructure planning to implement for effective management.

From the analysis of Table 4, an average of $31.85 \mathrm{~L}$ was recorded by someone in the town of Maradi. However, from the point of view total amount of wastewater generated per day per municipality, the municipality II has the lowest amount (18,870 Liter /Day). However, the mean value of the standard error (0.69) allow us to say that the difference between the three communes is not significant and can be explained by the number of people per municipality but especially by the mentality of the people.

Table 5 reflects the current state of discharge modes of gray wastewater from the town of Maradi. Indeed, three main methods are used in the town of Maradi to get rid of gray wastewater. Of these three, the most common method is the spill in the streets which includes more than half of those interviewed (60.30\%) against only $(19.11 \%)$ and $(0.29 \%)$ of people pouring their gray waste water respectively in the house and everywhere. This result could be explained on the one hand the cultural logic which says that all that is waste, all that is dirty or bad, must be rejected without, and outside the concession and also the mentality of many people are unaware of the dangers of poor management of wastewater. Hence, a large number of people evacuate the gray wastewater on public roads.

In addition, (20.30\%) of the interviewed people dump their gray waste water in the gutters. This could be explained by the fact that, often the households use the gutters to get rid of wastewater only if they pass the front of their houses. Thus, the results found in investigations confirm this to us with only a rate of (24.41\%) of households with gutters to their front against $75.59 \%$, which are either far away or they do not even have any gutters

Table 3. Global distribution of investigations by the house with a drainage system of gray wastewater (SEEUG).

\begin{tabular}{ccc}
\hline & Wastewater gray water disposal system & \\
\hline & Yes & No \\
\hline Number of households & 92 & 248 \\
Percentage (\%) & 27.05 & 72.95 \\
\hline
\end{tabular}

Table 4. Estimated amount of wastewater produced by each municipality.

\begin{tabular}{cccc}
\hline Municipality & Average amount of wastewater produced/person (Liter) & SD & Total quantity produced per day (Liter) \\
\hline 1 & 34.40 & \pm 1.20 & 32232.8 \\
2 & 30 & \pm 1.31 & 18870 \\
3 & 31.17 & \pm 1.08 & 35658.48 \\
Average & 31.85 & \pm 1.19 & 28920.42 \\
\hline
\end{tabular}

Table 5. Distribution of global surveys according to the mode of evacuation of gray wastewater from domestic activities.

\begin{tabular}{ccc}
\hline Mode of evacuation & Frequency \\
\hline In the house & 19.11 \\
On the street & 60.3 \\
In a gutter & 20.3 \\
Everywhere & 0.29 \\
\hline
\end{tabular}


in their neighborhoods. Hence the low rate of the discharge mode. The study of Apollinaire (2003), in the city of Niamey confirms our results but with only $9 \%$ of households that discharge wastewater into the gutters [4].

\section{Conclusions and Suggestions}

The wastewater management, including domestic, is one of the major issues in urban areas. However, it has not been given a key consideration, especially in underdeveloped countries. In the town of Maradi, the state of the liquid waste management revealed many shortcomings. We have retained thanks to field observations and various interviews that the management system is still weak (both organizationally and technically as financially). Also, the antisocial behavior of the population and the lack of collaboration among sanitation actors make waste management even more complicated in general. For liquid waste, especially domestic sewage, general observation to be made is that no special attention is paid to the collection, disposal and treatment of wastewater and faecal sludge. Thus, management translates simply to a transit of wastewater from place of production to the natural environment. The crucial problem of lack of drainage equipment rainwater, especially in the new quarters of the city of Maradi, should also be noted. It should be noted that the water for life can become source of disease when its quality deteriorates (wastewater).

At the end of this research work, we can make, toward Nigerien government, the following suggestions: 1) having a National Sanitation Policy, which serves as a reference framework for all stakeholders (this will allow harmonizing approaches, pooling energies and winning support from technical and financial partners); 2) ensuring the strict implementation of national standards for sewerage and septage management; 3 ) building sludge treatment plants in major cities of Niger; 4) taking into account in municipal development programs wastewater management problems and faecal sludge by the establishment of clear mechanisms from the collection to treatment and disposal; 5) strengthening the mechanisms for information, education and awareness; 6) ensuring the implementation and compliance with legal texts relating to sanitation issues and pollution in Niger.

\section{References}

[1] Boumediène, B. (2012) Modeling and Observation of Membrane Bioprocesses: Application to the Anaerobic Digestion. $\mathrm{Ph} . \mathrm{D}$. Thesis, under Joint Supervision between the University of Tlemcen (Algeria), and the University of Montpellier 2 (France).

[2] Hèssouwè, B. (2011) Autonomous Management of Wastewater Effluent and Water Pollution in Togo: Case of the City of Lomé. Master Thesis, University of Lomé, Lomé.

[3] Essinga Sapock, A.D. (2014) Waste Management in the City of Bertoua. Master Thesis, University of Yaoundé 2 , Yaoundé.

[4] Apollinaire, T. (2003) Domestic Solid Waste Management in Niamey, Niger: Attempt for a Sustainable Development Strategy. Ph.D. Thesis, University of Lyon, Lyon. 